\title{
Experimental validation and computational modeling of anti-influenza effects of quercetin-3-O-a-L-rhamnopyranoside from indigenous south African medicinal plant Rapanea melanophloeos
}

Parvaneh Mehrbod ${ }^{1,2^{*}}$ (D), Samad Nejad Ebrahimi ${ }^{3}$, Fatemeh Fotouhi ${ }^{1}$, Fatemeh Eskandari ${ }^{1}$, Jacobus N. Eloff ${ }^{4}$, Lyndy J. McGaw ${ }^{4}$ and Folorunso O. Fasina 2,5

\begin{abstract}
Background: Influenza A virus (IAV) is still a major health threat. The clinical manifestations of this infection are related to immune dysregulation, which causes morbidity and mortality. The usage of traditional medication with immunomodulatory properties against influenza infection has been increased recently. Our previous study showed antiviral activity of quercetin-3-O-a-L-rhamnopyranoside (Q3R) isolated from Rapanea melanophloeos (RM) (L.) Mez (family Myrsinaceae) against H1N1 (A/PR/8/34) infection. This study aimed to confirm the wider range of immunomodulatory effect of Q3R on selective pro- and anti-inflammatory cytokines against IAV in vitro, to evaluate the effect of Q3R on apoptosis pathway in combination with $\mathrm{H1N1}$, also to assess the physical interaction of Q3R with virus glycoproteins and RhoA protein using computational docking.

Methods: MDCK cells were exposed to Q3R and $100 C \mathrm{CID}_{50} / 100 \mu \mathrm{l}$ of $\mathrm{H} 1 \mathrm{~N} 1$ in combined treatments (co-, pre- and post-penetration treatments). The treatments were tested for the cytokines evaluation at RNA and protein levels by QPCR and ELISA, respectively. In another set of treatment, apoptosis was examined by detecting RhoA GTPase protein and caspase-3 activity. Molecular docking was used as a tool for evaluation of the potential anti-influenza activity of Q3R.

Results: The expressions of cytokines in both genome and protein levels were significantly affected by Q3R treatment. It was shown that Q3R was much more effective against influenza when it was applied in co-penetration treatment. Q3R in combination with H1N1 increased caspase-3 activity while decreasing RhoA activation. The molecular docking results showed strong binding ability of Q3R with M2 transmembrane, Neuraminidase of 2009 pandemic H1N1, N1 and H1 of PR/8/1934 and Human RhoA proteins, with docking energy of $-10.81,-10.47,-9.52$, -9.24 and $-8.78 \mathrm{Kcal} / \mathrm{mol}$, respectively.

*Correspondence: mehrbode@yahoo.com

${ }^{1}$ Influenza and Respiratory Viruses Department, Pasteur Institute of Iran,

Tehran, Iran

${ }^{2}$ Department of Veterinary Tropical Diseases, University of Pretoria, Pretoria,

South Africa

Full list of author information is available at the end of the article

(c) The Author(s). 2019 Open Access This article is distributed under the terms of the Creative Commons Attribution 4.0 International License (http://creativecommons.org/licenses/by/4.0/), which permits unrestricted use, distribution, and reproduction in any medium, provided you give appropriate credit to the original author(s) and the source, provide a link to the Creative Commons license, and indicate if changes were made. The Creative Commons Public Domain Dedication waiver (http://creativecommons.org/publicdomain/zero/1.0/) applies to the data made available in this article, unless otherwise stated. 
(Continued from previous page)

Conclusions: Quercetin-3-O-a-L-rhamnopyranoside from RM was significantly effective against influenza infection by immunomodulatory properties, affecting the apoptosis pathway and binding ability to viral receptors M2 transmembrane and Neuraminidase of 2009 pandemic H1N1 and human RhoA cellular protein. Further research will focus on detecting the detailed specific mechanism of Q3R in virus-host interactions.

Keywords: Influenza a virus, Quercetin-3-O-a-L-rhamnopyranoside, Cytokine, Apoptosis, Molecular docking

\section{Background}

Influenza A virus (IAV) is a respiratory tract pathogen that causes a high number of deaths and hospitalizations, including approximately 49,000 deaths and up to $35,600,000$ morbidity cases annually in the USA alone $[1,2]$. IAV recruits host cell machinery to support their replication and transportation inside the cell [3, 4]. In this regard, targeting cellular proteins in virus-host interaction pathways could be effective against influenza infection. The benefit of this approach is to reduce virus drug resistance. However, this strategy requires more understanding of the intracellular pathways that influenza A virus uses to replicate [3].

Several studies have suggested an association between inflammation and severe cases of IAV infection [5-7]. The host inflammatory response following influenza virus infection presents the host cells and the immune system with somewhat overwhelming effects. Host inflammatory response is a key factor in controlling virus proliferation but is also associated with lung damage, morbidity and death in the case of overwhelming inflammation [8]. Uncontrolled and exacerbated response to the virus may be associated with intense lung injury and death $[9,10]$.

In view of the foregoing, a growing number of studies have suggested that immunomodulatory strategies may improve disease outcome without affecting the ability of the host to deal with infection [11, 12]. Herbal medications have equally attracted tremendous attention [13, 14], as complementary therapies and preventive medicine [15-18].

Rho GTPase molecules, which can be modified posttranslationally, control a wide variety of signal transduction pathways. They can affect cell polarity, microtubule dynamics, membrane transport and transcription factor activities [19]. They are well-known proteins to regulate the intracellular signal transducers [20-22]. RhoA is one of the best-studied members of this family which is widely documented as a key regulator of cytoskeletal dynamics reorganization on membrane trafficking [23, 24]. Increasing evidence suggests a link between Rho proteins and apoptosis [25-27]. Several studies have also focused on the therapeutic effects of flavonoid compounds through Rho proteins expression and apoptosis pathway [28-30]. Different types of flavonoids have been identified as antiviral agents [31-34]. The reports of antiviral activity of flavonoids and derivatives against several viral infections through different mechanisms are increasing such as Adenovirus, Herpes Simplex Virus, Japanese Encephalitis Virus, Respiratory Syncytial Virus, HIV-1, Dengue Virus, Hepatitis C Virus and Zika Virus [35-41]. The potent antiviral effect of flavonoids against influenza virus infection [42-44] and immunomodulatory effects of flavonoids in different viral infections [45-47] have been reported as well.

Quercetin from the flavonoid group of plant compounds has been studied in small clinical trials [48]. There are limited studies on immunomodulatory effects of quercetin on influenza infection. One such study indicated the inhibitory activity of quercetin on influenza infection in the early stage of entry [49]. Q3R from Houttuynia cordata demonstrated strong anti-influenza A/WS/33 virus activity, reducing the formation of visible $\mathrm{CPE}$, and inhibited virus replication in the initial stage of virus infection [50].

The biological activity of flavonoids depends on the configuration, the total number of hydroxyl groups, and substitution of functional groups about their nuclear structure [34].

Quercetin belongs to the class called flavonols that cannot be produced in the human body but only in plant material and products [51]. It is one of the important flavonoid compounds isolated from more than twenty plant material from USA, Europe, and eastern countries which is known for its different properties especially anti-inflammatory activities $[52,53]$. We also reported quercetin isolation from Rapanea melanophloeos (Myrsinaceae family) an indigenous South African plant for the first time [54].

In continuation of our previous study [54], this research was designed to confirm and reveal the additional immunomodulatory activity of Q3R and its effect on the apoptosis pathway, in controlling influenza infection. Computational molecular docking was also performed to screen the potential binding ability of Q3R with neuraminidase/hemagglutinin glycoproteins and M2 transmembrane from H1N1, and Human RhoA.

\section{Materials and methods} Immunomodulatory evaluation

The quercetin-3-O- $\alpha$-L-rhamnopyranoside was isolated from Rapanea melanophloeos [55]. The antiviral activity of Q3R against influenza infection was evaluated in our 
earlier study [54]. The non-cytotoxic concentration (NCTC) of Q3R $(150 \mu \mathrm{g} / \mathrm{ml})$ was exposed to the cell in combination with $100 \mathrm{CCID} \mathrm{D}_{50} / 100 \mu \mathrm{l}$ of H1N1. Its immunomodulatory capacity was confirmed by testing cellfree supernatants treated for $48 \mathrm{~h}$ pointing at TNF- $\alpha$ and IL-27 previously [54]. In this study, IL-6 and CCL-2 as pro-inflammatory cytokines and IFN- $\beta$ as antiinflammatory cytokines were measured additionally at RNA and protein levels by qPCR and ELISA, respectively to add more values to $\mathrm{Q} 3 \mathrm{R}$ immunomodulatory properties profile.

The molecular assay was conducted as stated before [54]. The primers specifications are shown in Table 1. The primers used for housekeeping genes were mentioned in our previous study [54].

The IL- 6 cytokine protein was quantified by quantitative sandwich Picokine ELISA kits (Boster Biological Technology, CA, USA) according to the manufacturer's instruction as stated previously [54]. The IFN- $\beta$ and CCL2 were evaluated by sandwich geneILNB1 kit (EIAab Science Co, China) and sandwich Ready-SET-Go kit (Invitrogen, USA) according to the manufacturers' instructions, respectively. The optical densities were measured at $450 \mathrm{~nm}$ wavelength using microplate reader (Anthos 2020, version 2.0.5). The concentrations were calculated according to the corresponding reaction standard formula. All the data were statistically analyzed by SPSS version 22. Analysis of variance (ANOVA), Post hoc Tukey test was used to determine the significance of difference among the treatments $(P<0.05)$.

\section{Sample preparation for protein evaluation}

MDCK cells were cultured in T-75 flasks (Orange Scientific, Belgium). The cells were simultaneously treated with Q3R $(150 \mu \mathrm{M})$ and Y-27632 $(10 \mu \mathrm{M})$ (RhoA inhibitor) in the presence or absence of H1N1 (100 TCID 50 / $0.1 \mathrm{ml}$ ) for $48 \mathrm{~h}$. Untreated cells and virus-inoculated cells were considered as negative and positive controls, respectively. Cells were scraped and collected in ice cold PBS and centrifuged to form pellet. The cell pellet was re-suspended and homogenized in RIPA buffer mixed with protease inhibitor cocktail. The homogenate was centrifuged $\left(15,000 \mathrm{~g} 4{ }^{\circ} \mathrm{C} 15 \mathrm{~min}\right)$. The pellet was discarded and supernatant was stored at $-80{ }^{\circ} \mathrm{C}$ for further evaluation. The protein concentration in each sample was quantified using Bradford Assay by Microplate reader (BioTek EL 800, US) [56].

\section{RhoA protein immunoblotting}

The protein samples $(50 \mu \mathrm{g})$ were fractioned using $15 \%$ sodium dodecyl sulfate polyacrylamide gel electrophoresis (SDS-PAGE) and transferred to nitrocellulose membrane (Bio-Rad) by vertical semi-dry electroblotting. Following $1 \mathrm{~h}$ blocking of the membranes using 1\% BSA as blocking buffer and washing steps with Tris-buffered saline (TBS)-Tween, the membranes were incubated overnight with primary antibodies (Rabbit primary polyclonal anti-RhoA, Merck, Germany, 1:1000; and Rabbit primary monoclonal anti- $\beta$-actin, Cell Signaling Technology, USA, $1: 1000)$ at $4{ }^{\circ} \mathrm{C}$. Followed by washing, the membranes were exposed to AP-conjugated secondary antibody (Goat polyclonal anti-Rabbit IgG, Abcam, UK, $1: 1000)$ for $2 \mathrm{~h}$ at room temperature. The enzymatic reaction was visualized using a BCIP-NBT substrate (Merck, Germany). The $\beta$-actin was detected as housekeeping protein for loading control. The blots were scanned and the protein bands intensities were quantified using Image J 1.46r software. For each sample, signal intensity was normalized to the negative control and internal control.

\section{Caspase-3 cellular activity assay}

The cells were cultured in T-75 flasks (Orange Scientific, Belgium) and treated as mentioned above. Untreated cells were considered as negative control. The caspase- 3 included in the kit was used as a positive control. Following cell lysis, the proteins were extracted and quantified using Bradford Assay. The conversion factor of the reader was determined before beginning the assay. The caspase-3 Cellular Activity Assay Kit (Merck, Germany) was used for this test. The substrate standard [50 $\mu \mathrm{M} \mathrm{p}$ nitroaniline (pNA) in the assay buffer] $(100 \mu \mathrm{l})$ was added to 2 wells of the plate. The average A405 using $100 \mu \mathrm{l}$ assay buffer as a blank was determined. This calculation was based on the concentration of $\mathrm{p}$ nitroaniline in the calibration standard $(50 \mu \mathrm{M})$.

Table 1 The specification of the primers for amplification of the targeted genes

\begin{tabular}{|c|c|c|c|c|c|c|}
\hline Gene name & Primer sequence (5' to $3^{\prime}$ ) & Accession number & Position & Size (bp) & $\operatorname{Tm}\left({ }^{\circ} \mathrm{C}\right)$ & $\begin{array}{l}\text { Optimized annealing } \\
\text { temperature }(\mathrm{Ta})\left({ }^{\circ} \mathrm{C}\right)\end{array}$ \\
\hline IL-6-F & GTTCGGATAATGTAGCCT & NM_001003301.1 & $633-650$ & 135 & 40.6 & 53.9 \\
\hline IL-6-R & TCACAGAGAACAACATAACT & & $751-768$ & & 40.5 & \\
\hline$C C L-2-F$ & GTGATCTTCAAGACCGTCCTAA & NM_001003297.1 & $191-212$ & 130 & 47.9 & 59.5 \\
\hline$C C L-2-R$ & TTCAGAGTGAGTATTCATGGCTT & & $299-321$ & & 46.6 & \\
\hline IFN- $\beta-F$ & AAACTTCACCTGGGACAA & NM_001135787.1 & $390-407$ & 118 & 40.6 & 55.9 \\
\hline IFN- $\beta-R$ & TICTGCTTGGACTATTGT & & & & 39.5 & \\
\hline
\end{tabular}


For caspase-3 cellular activity evaluation in the samples, the protein extracts were added to the 96-well plate $(10 \mu \mathrm{l})$ which already had assay buffer $(40 \mu \mathrm{l})$. A well with only assay buffer was used as blank. The plate was incubated at room temperature for $10 \mathrm{~min}$ to allow inhibitor/enzyme interaction. The reaction was started by adding $50 \mu \mathrm{l}$ caspase-3 Substrate I, Colorimetric. The absorbance was measured at $405 \mathrm{~nm}$. Data were recorded every $10 \mathrm{~min}$ for $30 \mathrm{~min}$ after adding the substrate.

\section{Statistical analysis}

Data presented as means \pm SD were analyzed using SPSS 18.0. One-way analysis of variance (ANOVA) post-hoc LSD test was used to analyze the effect of treatments on RhoA protein expression. All charts were plotted using GraphPad Prism 5.0. For all tests, $P \leq 0.05$ was considered significant.

\section{Molecular docking}

The 2D structures of the compound were created by ChemDraw Professional 15.0 and 3D structures were generated by Chem3D suite. The SDF format of structures was saved and used for docking study. The energy minimization of the 3D structure was performed by Lig Prep module implemented in Schrodinger 2015-2, using Maestro 10.2 platform. The crystal structures of influenza neuraminidase of A/Brevig Mission/1/1918 H1N1 strain (3BEQ), PR/8/1934 human strain $\mathrm{H} 1$ hemagglutinin (1RU7), avian H5 haemagglutinin (1JSN), 2009 pandemic H1N1 neuraminidase (3TI6), M2 transmembrane (2KQT), N1 neuraminidase (2HTY) and Human RhoA (1A2B) were selected from the previous publications $[57,58]$ and downloaded from protein data bank (www.rcsb. org). The protein preparation for docking was performed using Protein Preparation Wizard on Maestro 10.2 Schrodinger suite. The protein preparation included deleting of water molecules, assigning formal charge and bond order of protein, adding all missing hydrogen atoms, loops and side chains to crystal structures. Then the hydrogen network was refined and hydrogen minimization was carried out by OPLS3 force field parameter. The receptor grid box was generated with a box size of $25 \AA \times 25 \AA \times 25 \AA$ using the Grid generation application. The Q3R and native ligands Oseltamivir, Rimantadine, Arbidol, Guanosine 5' do]triphosphate (GMP-PNP, Gpp(NH)p) were docked to grid files of proteins by Glide extra precision (XP) mode.

\section{Results}

\section{Relative expression analysis}

The relative expression analysis of the cytokines genes was calculated as fold change compared to the positive control. Data are shown in Fig. 1. As observed in the Figure, H1N1 inoculation increased IL-6 and CCL-2 expressions 16.62 and 34.18 fold, respectively, but in combination treatments, they all showed decrements, especially in the co-penetration procedure the compound decreased IL-6 and CCL-2 expressions highly significantly 0.0004 and 5.2221 fold, respectively.

With regards to IFN- $\beta$, H1N1 inoculation decreased this cytokine 0.0004 fold while it increased 16.11 fold on average for all combined treatments with no significant difference as compared with each other.

\section{Cytokines analysis with ELISA}

The levels of cytokines proteins in supernatants of MDCK cell culture at $48 \mathrm{~h}$ after exposure were detected. The percentage of changes of all cytokines is shown in Table 2. As shown in the Table 2, all combination treatments were effective in modulating the cytokine protein levels, especially in the co-penetration procedure.

\section{RhoA immunoblotting results}

The expression level of RhoA protein was affected by different treatments (Fig. 2). As shown in the Western Blot image, Q3R treatment depleted this protein expression. The increase of RhoA in the H1N1-inoculated sample was evident. The combination treatment of Q3R and H1N1 showed increment in the expression of RhoA but not so much as H1N1 sample. Y-27632 is a selective inhibitor of Rho-associated protein kinases also decreased RhoA protein expression.

Band densitometry and statistical analysis (Fig. 3) verified that in comparison with the H1N1-inoculated sample, Q3R treatment depleted this protein expression highly significantly $(P<0.001)$. The combination treatment of Q3R and $\mathrm{H} 1 \mathrm{~N} 1$ decreased the expression of RhoA significantly $(P<0.01)$. B-actin as housekeeping protein remained unchanged after the treatments.

\section{Caspase- 3 cellular activity assay results}

In this assay, the effect of Q3R and H1N1 was evaluated on the caspase-3 activity. As shown in Fig. 4, Q3R treatment increased caspase-3 activity with a slight decrement by increasing time but showed the highest values compared to H1N1. However, in H1N1-inoculated sample, caspase- 3 activity showed decline, which is indicative of RhoA activity increment by the virus. The combination treatment of Q3R with $\mathrm{H} 1 \mathrm{~N} 1$ showed intermediate values of caspase- 3 activity in all incubation times with a slight increment by increasing time.

\section{Molecular docking results}

The interaction between Q3R and influenza hemagglutinin/ neuraminidase/ M2 and RhoA proteins was carried out by molecular docking study. For this purpose, five crystal structures were selected based on the previously published data described in the experimental section. The results of interactions and docking scores were reported in Table 3. The Q3R 

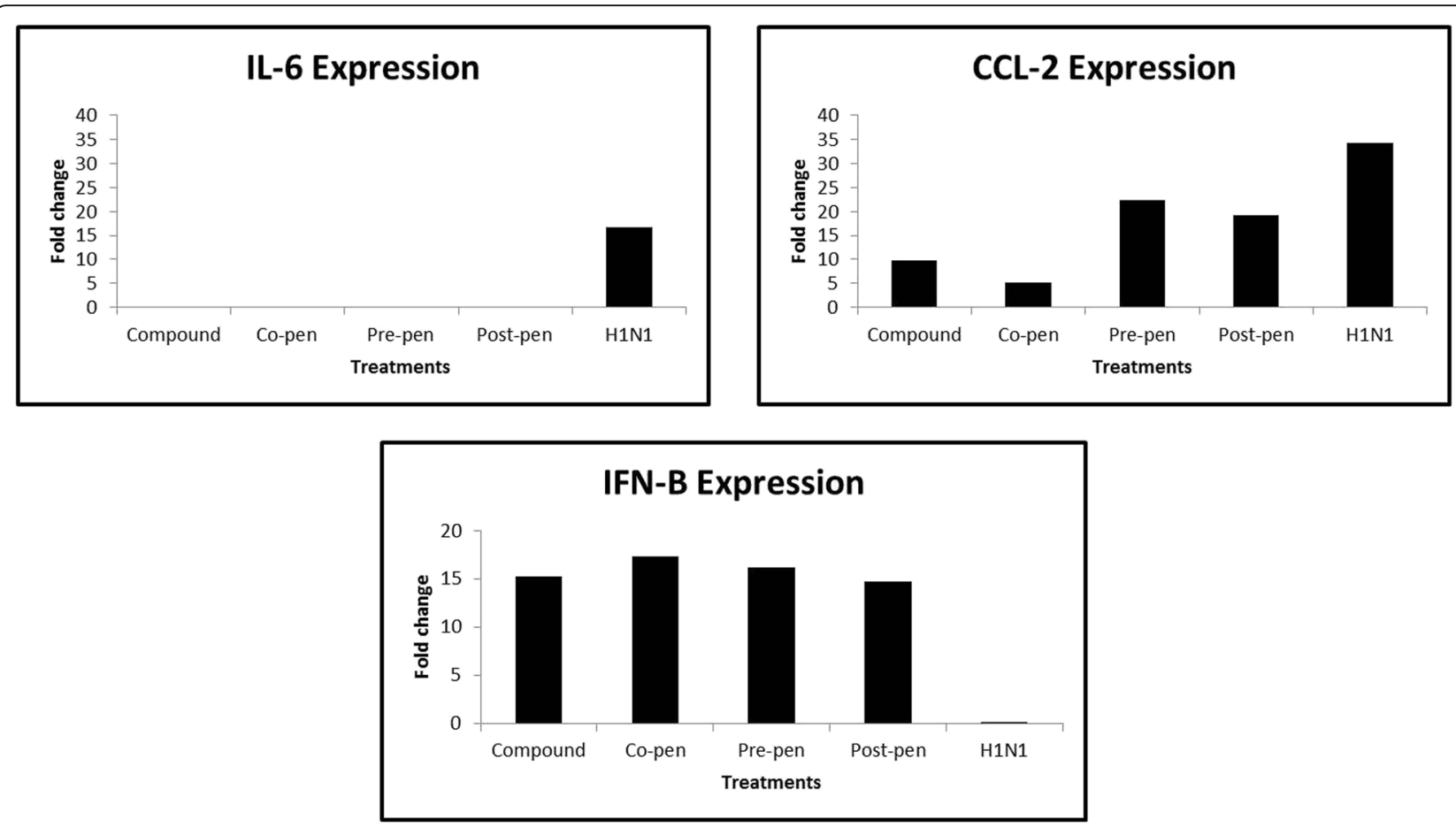

Fig. 1 Relative expression analysis $(\Delta \Delta \mathrm{Cq})$ of the cytokines compared to the positive control

showed excellent docking score with M2 transmembrane (2KQT), Neuraminidase of 2009 pandemic H1N1 (3TI6), N1 neuraminidase (2HTY) and PR/8/1934 Human strain H1 hemagglutinin (1RU7) by the values of $-10.81,-10.47$, 9.52 and $-9.24 \mathrm{kcal} / \mathrm{mol}$, respectively. Also the interaction of Q3R and RhoA (1A2B) showed high affinity with docking score of $-8.78 \mathrm{Kcal} / \mathrm{mol}$ comparing to the GMP-PNP, $\mathrm{Gpp}(\mathrm{NH}) \mathrm{p}$ with value of $-5.55 \mathrm{Kcal} / \mathrm{mol}$, the strong hydrogen bonding between Q3R and GLH119, ASP151, ARG292, TYR406 and SER249 were involved in this high affinity (Fig. 5c). The Q3R showed a much better docking score with studied targets comparing to the antiviral drugs oseltamivir, rimantadine, arbidol and GMP-PNP, Gpp(NH)p as positive controls (Table 3).

\section{Discussion}

The modification and manupulation of cytokines production is a critical step in influenza pathogenesis, which can recruit a variety of innate immune cells [59]. In this study, in completing our previous study $[54,60]$, interleukin-6 (IL-6) and chemokine C-C motif ligand 2
(CCL-2) from the category of pro-inflammatory cytokines and interferon- $\beta$ (IFN- $\beta$ ) from the category of anti-inflammatory cytokines were tested at the genome and protein levels.

The cytokine production was affected by quercetin during influenza course. Q3R was able to significantly decrease the IL- 6 production to $0.0004,0.0202$ and 0.0733 fold in co-, pre- and post-penetration treatments, respectively at the genome level (Fig. 1). This decrement was observed in protein level as well. However, the copenetration treatment showed more elimination to $76.66 \%$ (Table 2). This cytokine is highly correlated with high body temperature during influenza illnesses and infection [61, 62], and strong up-regulation of this cytokine can predict the severity of the infection [63]. Consequently, Q3R has a high potential to decrease the fever and severity of influenza illnesses by regulating the excessive innate inflammatory reaction.

Chemokine (C-C motif) ligand 2 (CCL-2) was one of the affected chemokines evaluated in this study. This chemokine recruits memory $\mathrm{T}$ cells, exudate macrophages

Table 2 Cytokines protein percentages of changes in MDCK culture supernatants at $48 \mathrm{~h}$ treatment

\begin{tabular}{llll}
\hline Treatment & IL-6\% change to H1N1 & CCL-2\% change to H1N1 & IFN- $\beta$ \% change to H1N1 \\
\hline Co-pen & -76.659 & -52.488 & -10.511 \\
Pre-pen & -49.937 & -22.761 & 4.955 \\
Post-pen & -45.553 & -10.607 & -5.706
\end{tabular}

Percentages of cytokines changes compared to H1N1, as determined by ELISA, are expressed as pg/ml $(N=2)$ for $48 \mathrm{~h}$ incubation time 


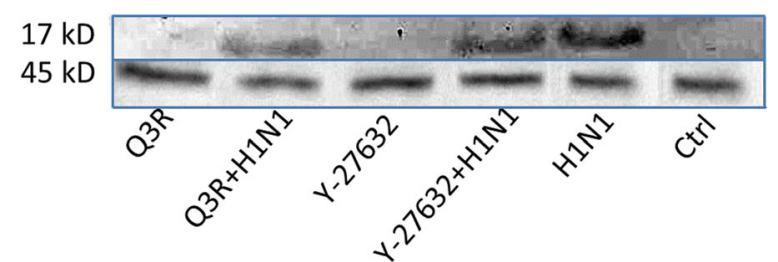

Fig. 2 Modulation of the RhoA protein expression. MDCK cells were treated with Q3R and Y-27632 in the presence or absence of H1N1 for $48 \mathrm{~h}$. The blot is typical of two independent experiments with similar results. Each blot was scanned and imaged separately

(exMACs) and monocytes to the site of the infection $[60,63,64]$. Attraction of these CCR2 ${ }^{+}$inflammatory cells to the site would lead to naive $\mathrm{T}$ cell proliferation, $\mathrm{NO}$ synthesis 2 (NOS2) and TNF- $\alpha$ production [63]; however, the extreme recruitment of these cells causes extra cytokine production and apoptosis induction by tumor necrosis factor-related apoptosis inducing legend (TRAIL) activation [65]. In the children with deadly acute encephalopathy associated with IAV, high concentrations of CCL-2 and CSF have been reported [66]. Decrement in CCL-2 and mononuclear cells in the infection site can effectively control the virus infection by improving the condition without affecting the $\mathrm{CD}^{+} \mathrm{T}$ cell expansion [67]. In the current study, Q3R showed the ability to significantly decrease the CCL-2 protein production and gene expression especially in the co-penetration treatment to $-52.488 \%$ (Table 2) and 5.2221 fold (Fig. 1), respectively compared to $\mathrm{H} 1 \mathrm{~N} 1$ inoculation which can decrease the mortality associated with the highly pathogenic influenza viruses.

IFN- $\beta$ is a type I interferon and inhibitor of inflammation [68]. It can shift the cytokine networks in favor of anti-inflammatory effects [69]. In the study of protein level, H1N1 showed a mild increase in IFN- $\beta$ protein compared to the negative control, however, no significant difference was observed at the protein level between H1N1 inoculation and combined treatments. The gene expression of IFN- $\beta$ decreased in $\mathrm{H} 1 \mathrm{~N} 1$ sample by 0.0004 fold but in all combined treatments it showed increments at the same level (Fig. 1). This can be referred to excessive intracellular viral NS1 protein that prevents the induction of beta interferon [70]. In addition, referred to our previous study which showed elevated levels in TNF- $\alpha$ production in $\mathrm{H} 1 \mathrm{~N} 1$ sample and its significant decrement when subjected to Q3R [54], it is reported that increase of TNF- $\alpha$ can inhibit the

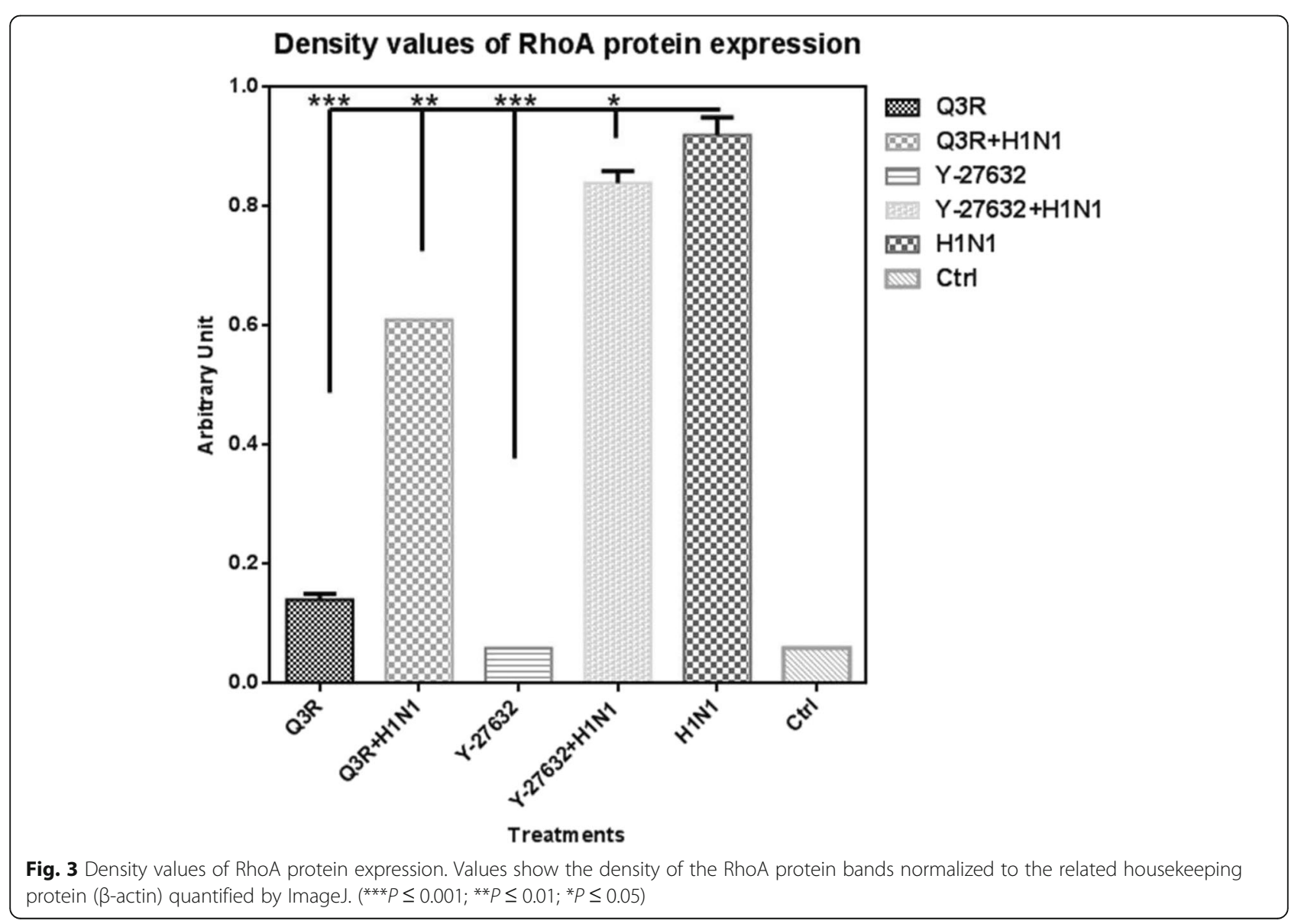




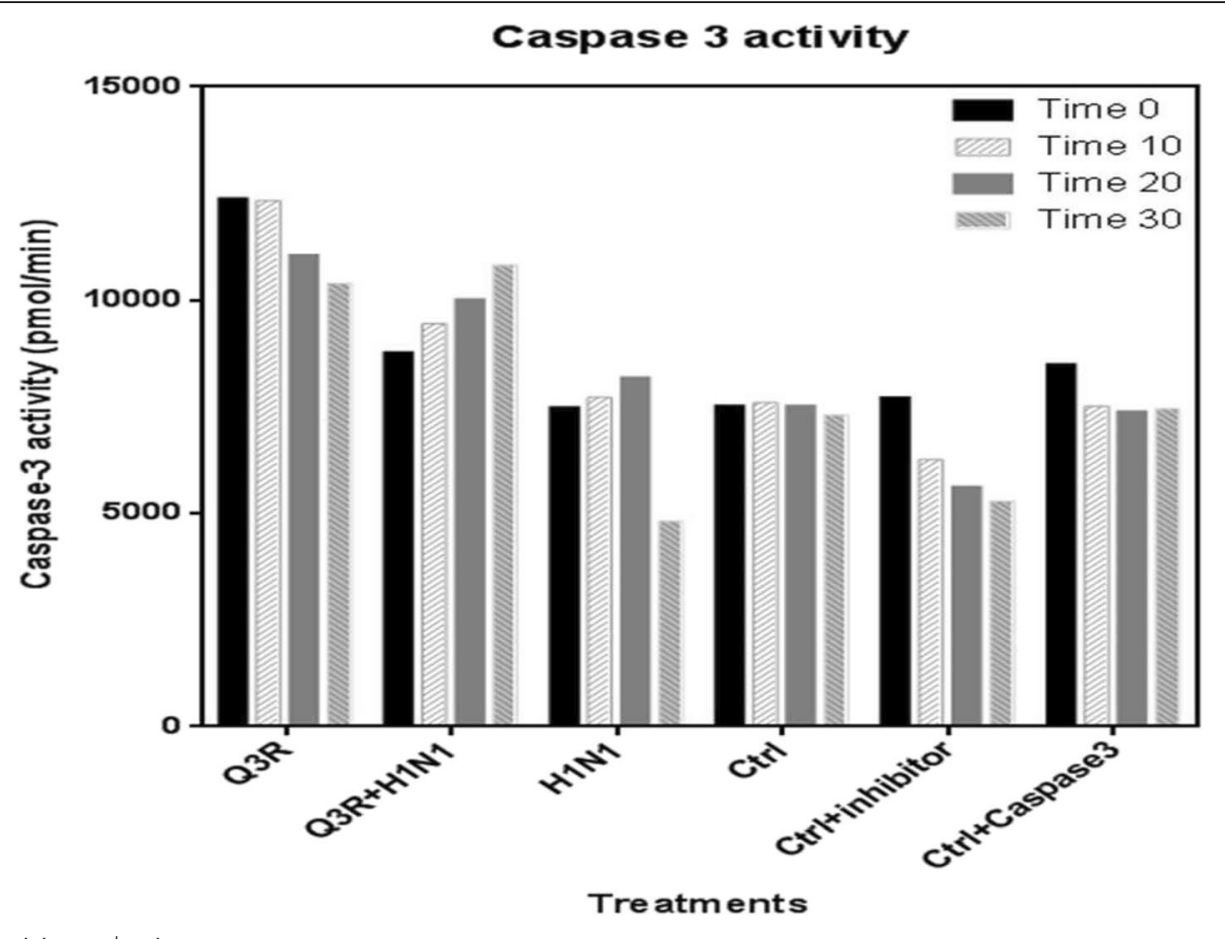

Fig. 4 Caspase-3 activity evaluation

production of IFN $\alpha / \beta$ [54]. This outcome might be the reason for this effect of Q3R which shows that Q3R does not act through IFNs.

Thus, the compound Q3R could interrupt the effect of the influenza virus on the cytokines which could decrease pro-inflammatory and increase anti-inflammatory cytokines.

It has been studied that active RhoA prevents endothelial apoptosis. Therefore, inhibition of Rho in endothelial cells not only reduced the expression of anti-apoptotic Bcl-2 and Mcl-1 and increased proapoptotic Bid protein levels, but also, activated caspase-9- and -3-dependent programmed cell death (apoptosis) [25]. A recent study highlighted that RhoA might be important for the proliferation and apoptosis in lung cancer cells. Alterations in caspase- 3 may be the underlying molecular mechanisms associated with the effect of RhoA on cell proliferation and apoptosis [71].

Quercetin is a flavanol compound occurring naturally in plant materials. It increased the expressions of RhoA and Rho-associated, coiled-coil containing protein kinase-1 (ROCK1), but inhibited the expression of NFкB p65 in SAS Human oral cancer cells. This role of quercetin was mentioned to be associated with the down-regulation of PKC and RhoA by blocking MAPK and PI3K/AKT signaling pathways and NF-kB [29]. Rho GTPase-mediated mechanisms of isoquercitrin were tested in a study. It was shown that RhoA underwent translocation to the cytoplasm upon treatment with isoquercitrin. Thus, it affected RhoA localization preventing the translocation to the plasma membrane [28]. Flavonoids have also shown protection against apoptosis on

Table 3 The docking energy of Q3R with the studied receptors

\begin{tabular}{|c|c|c|c|c|c|}
\hline \multirow[t]{2}{*}{ Protein (PDB ID) } & \multicolumn{5}{|c|}{ Docking energy (Kcal/mol) } \\
\hline & Q3R & Oseltamivir & Rimantadine & Arbidol & GMP-PNP, Gpp(NH)p \\
\hline Neuraminidase of A/Brevig Mission/1/1918 (3BEQ) & -6.58 & -7.40 & & & \\
\hline PR/8/1934 Human H1 (1RU7) & -9.24 & & & -4.51 & \\
\hline Hemagglutinin of Avian H5 (1JSN) & -6.87 & -8.08 & & & \\
\hline Neuraminidase of 2009 pandemic H1N1 (3T16) & -10.47 & -7.06 & & & \\
\hline M2 transmembrane (2KQT) & -10.81 & & -5.51 & & \\
\hline N1 neuraminidase (2HTY) & -9.52 & -4.68 & & & \\
\hline Human RHOA (1A2B) & -8.78 & & & & -5.55 \\
\hline
\end{tabular}



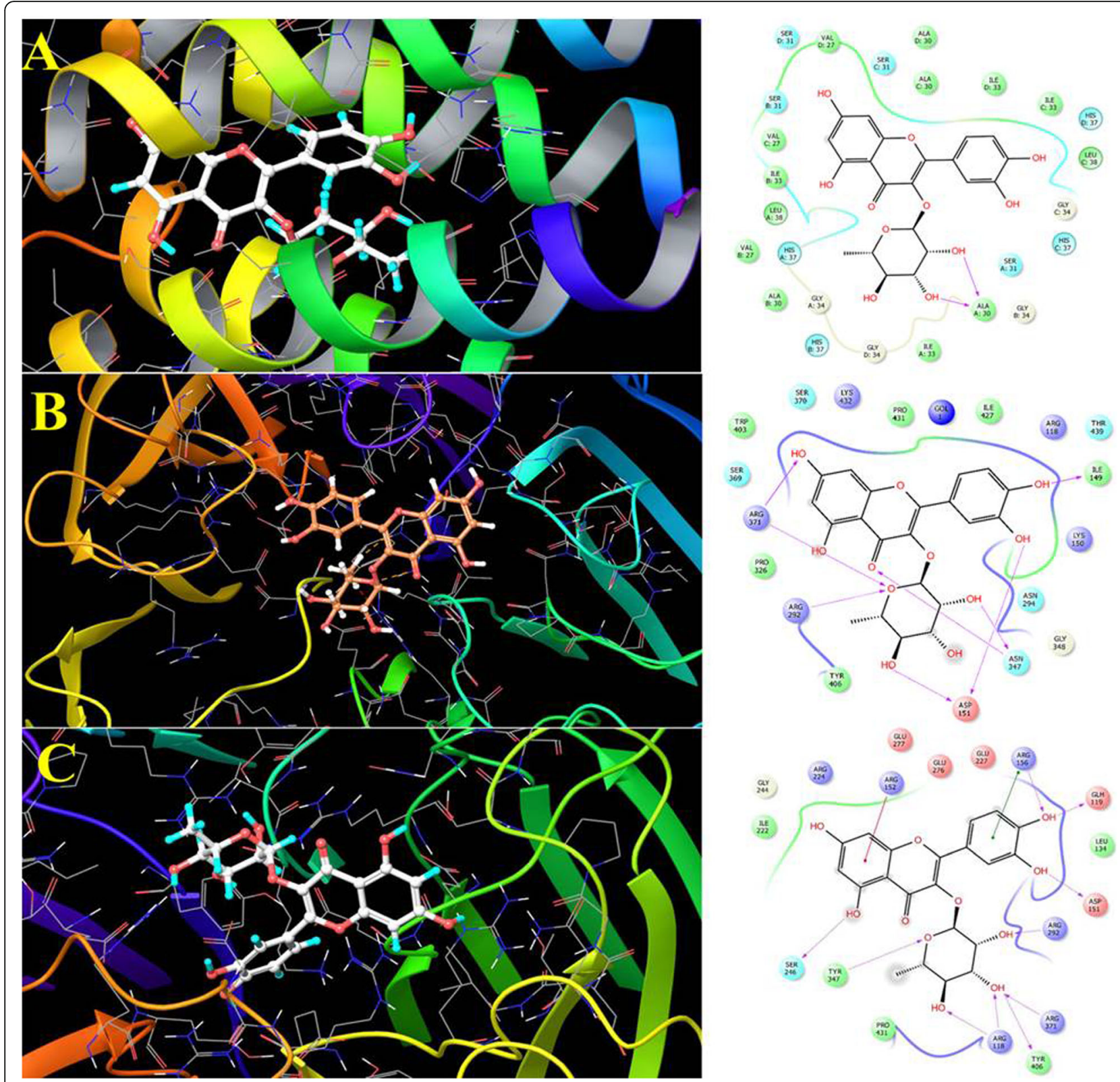

Fig. 5 The 2D interaction and 3D docking model of Q3R with a) M2 transmembrane (2KQT) and b) Neuraminidase 2009 pandemic H1N1 (3T16) receptors from influenza virus and $\mathbf{c}$ ) human Ras homolog family member A (RhoA). The docking was performed using Glide application using Schrödinger drug discovery suite

neurons involving c-Jun N-terminal kinase (JNK), c-Jun and caspase-3 [30].

Different quercetin derivatives may play different roles in signaling pathways depending on the type of cell or disease. The effect of quercetin-3-O-(2"-galloyl)- $\alpha-1$ rhamnopyranoside (QGR) was investigated on TRAILinduced apoptosis in human keratinocytes. Treatment with QGR prevented TRAIL-induced apoptosis-related protein activation, but quercetin had an additive effect on TRAIL-induced apoptosis-related protein activation and cell death [72]. In a recent study, quercetin-3-O- $\alpha$ -
L-rhamnopyranoside (Q3R) decreased the oxidative stress in human umbilical vein endothelial cells (HUVECs) by promoting the nuclear transfer of nuclear factor erythroid 2-related factor 2 (Nrf2) and heme oxygenase-1 by activating autophagy. This study supported the use of quercetin3-O- $\alpha$-L-rhamnopyranoside (Q3R) as a health supplement to alleviate oxidative stress [73].

In regards to apoptosis pathway and RhoA and apoptosis interaction [25], it was found in this study that in combination treatment of Q3R with H1N1, RhoA expression decreased and caspase-3 activity increased 
compared to the H1N1 sample. Caspase-3, a member of the interleukin-1 $\beta$ converting enzyme (ICE) family of cysteine proteases, is one of the principal caspases found in the apoptotic cells. The highest values of caspase- 3 activity in Q3R sample compared to H1N1 correlates with the RhoA decrement in Q3R treatment. And intermediate value of caspase-3 activity in combination treatment of Q3R with H1N1 was indicative of regulatory role of Q3R on RhoA activity against viral molecular pathway.

The molecular docking results showed strong binding ability of Q3R with M2 transmembrane, Neuraminidase of 2009 pandemic H1N1, N1 neuraminidase, PR/8/1934 Human strain $\mathrm{H} 1$ and Human RhoA, with docking energy of $-10.81,-10.47,-9.52,-9.24$ and $-8.78 \mathrm{Kcal} /$ mol, respectively. Regarding the docking study, there are three essential types of interactions with the enzyme active site including hydrogen bond, Pi-Pi staking, and hydrophobic interactions. The Q3R showed strong interactions with M2 transmembrane (2KQT) residues, namely with ALA A30, ILE B33, VAL D27, VAL C27, ALA D30, phenolic and sugar moieties (Fig. 5a). The Q3R showed several hydrogen-bonding interactions with 3 TI6 receptors, namely with ASP151, ASN347, and ILE149, together with Pi-Pi staking with ILE149, ILE427, PRO431, TRP403 and TYR406 from phenolic and sugar moieties. This implies that the presence of both parts is essential for high affinity with ligand and receptor.

\section{Conclusions}

In conclusion, while our previous studies showed the safety effects of Q3R over amantadine and oseltamivir, and also supporting data from the current study, in vitro evaluation of the consequences of Q3R revealed this natural compound has the potential to alleviate influenza infection by modulating the inflammatory response, affecting the apoptosis pathway and efficiently improve the outcome of the influenza disease.

Further details on the docking results showed that the structural features of Q3R might be helpful for further drug design and development. We concluded that Q3R can inhibit the virus affecting the virus penetration/adsorption directly. Correspondingly, it showed the ability to indirectly dominate the severity of the disease by changing the cytokines pattern and affecting the apoptosis pathway. Thus, the concurrent application of quercetin-3-O- $\alpha$-L-rhamnopyranoside with influenza A virus infection is highly effective in influenza infection modulation. Therefore, understanding and targeting the cellular proteins and intracellular pathways required for influenza replication are valuable and beneficial to prevent or treat this infection more efficiently. Further in vivo evaluation can also assist in understanding the benefits of quercetin against influenza disease in a perceptible way.

\section{Abbreviations}

ANOVA: Analysis of variance; $\mathrm{CCID}_{50}$ : Cell culture infectious dose $50 ; \mathrm{CCL}$ 2: Chemokine C-C motif ligand 2; ELISA: Enzyme-linked immunosorbent assay; exMACs: Exudate macrophages; HA: Hemagglutination;

HUVECs: Human umbilical vein endothelial cells; IAV: Influenza A virus; ICE: Interleukin-1 $\beta$ converting enzyme; MDCK: Madin Darby Canine Kidney; NA: Neuraminidase; NCTC: Noncytotoxic concentration; NOS2: NO synthesis 2; Nrf2: Nuclear factor erythroid 2-related factor 2; OD: Optical Density; PBS: Phosphate-buffered saline; Q3R: Quercetin-3-O-a-L-rhamnopyranoside; QPCR: Quantitative PCR; RM: Rapanea melanophloeos; TRAIL: Tumor necrosis factor-related apoptosis-inducing legend; Trypsin-TPCK: Tosylamide

Phenylethyl Chloromethyl Ketone-treated Trypsin

\section{Acknowledgments \\ Our sincere gratitude goes to Phytomedicine Laboratory, University of Pretoria and Influenza Department, Pasteur Institute of Iran to provide the facilities. We thank group of Molecular Modeling, University of Basel, for assisting in the molecular modeling part.}

\section{Authors' contributions}

PM, FOF, LJM co-defined the research theme. PM designed the methods and experiments. JNE, LM provided the facilities of the Phytomedicine Laboratory. FF provided the facilities for antiviral work. PM carried out the laboratory experiments with the assist of FE. SNE assisted in molecular docking evaluation and interpretation. PM analyzed the data, drafted the manuscript and worked on the associated data collection and their interpretation. PM, SNE, LJM, FOF revised the manuscript critically for editorial and important intellectual content. All authors have seen and approved the manuscript.

\section{Funding}

This study was supported by the National Research Foundation under the cost center number N00882, project 98033RUN, South Africa. The funder had no involvement in the collection, analysis, and interpretation of data; writing of the report; and the decision to submit the article for publication.

\section{Availability of data and materials}

The datasets used and/or analyzed during the current study are available from the corresponding author on reasonable request.

\section{Ethics approval and consent to participate}

Not applicable.

\section{Consent for publication}

Not applicable.

\section{Competing interests}

The authors declare that they have no competing interests. Prof Jacobus N Eloff is a section editor and Prof Lyndy J McGaw is an associate editor of BMC Complementary and Alternative medicine.

\section{Author details \\ ${ }^{1}$ Influenza and Respiratory Viruses Department, Pasteur Institute of Iran, Tehran, Iran. ${ }^{2}$ Department of Veterinary Tropical Diseases, University of Pretoria, Pretoria, South Africa. ${ }^{3}$ Department of Phytochemistry, Medicinal Plants and Drugs Research Institute, Shahid Beheshti University, Tehran, Iran. ${ }^{4}$ Phytomedicine Programme, Department of Paraclinical Sciences, University of Pretoria, Pretoria, South Africa. ${ }^{5}$ ECTAD, Food and Agriculture Organization of the United Nations (FAO), Dar es Salaam, Tanzania.}

Received: 5 May 2019 Accepted: 27 November 2019

Published online: 02 December 2019

\section{References}

1. Rolfes MA, Foppa IM, Garg S, Flannery B, Brammer L, Singleton JA, et al. Annual estimates of the burden of seasonal influenza in the United States: a tool for strengthening influenza surveillance and preparedness. Influenza Other Resp. 2018;12(1):132-7.

2. Thompson MG, Shay DK, Zhou H, Bridges CB, Cheng PY, Burns E, et al. Estimates of deaths associated with seasonal influenza - United States, 1976-2007. MMWR-Morbid Mortal W. 2010;59(33):1057-62. 
3. Haidari M, Zhang W, Ganjehei L, Muzammil A, Zhenping C. Inhibition of MLC phosphorylation restricts replication of influenza virus-a mechanism of action for anti-influenza agents. PLoS One. 2011;6(6):e21444.

4. Whittaker GR. Intracellular trafficking of influenza virus: clinical implications for molecular medicine. Expert Rev Mol Med. 2001;3:1-13.

5. Rothberg MB, Haessler SD. Complications of seasonal and pandemic influenza. Crit Care Med. 2010;38:e91-e7.

6. de Jong MD, Simmons CP, Thanh TT, Hien VM, Smith GJ, Chau TN, et al. Fatal outcome of human influenza a ( $\mathrm{H} 5 \mathrm{~N} 1)$ is associated with high viral load and hypercytokinemia. Nat Med. 2006;12:1203.

7. Perrone LA, Szretter KJ, Katz JM, Mizgerd JP, Tumpey TM. Mice lacking both TNF and IL-1 receptors exhibit reduced lung inflammation and delay in onset of death following infection with a highly virulent H5N1 virus. J Infect Dis. 2010;202(8):1161-70.

8. Tavares LP, Teixeira MM, Garcia CC. The inflammatory response triggered by influenza virus: a two edged sword. Inflamm Res. 2017;66(4):283-302.

9. Hendrickson CM, Matthay MA. Viral pathogens and acute lung injury: investigations inspired by the SARS epidemic and the 2009 H1N1 influenza pandemic. Semin Resp Crit Care M. 2013;34(4):475-86.

10. Bruder D, Srikiatkhachorn A, Enelow RI. Cellular immunity and lung injury in respiratory virus infection. Viral Immunol. 2006;19(2):147-55.

11. Mehrbod P, Hair-Bejo M, Tengku Ibrahim TA, Omar AR, El Zowalaty M, Ajdari

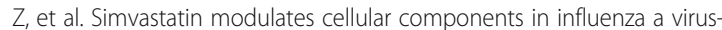
infected cells. Int J Mol Med. 2014;34:61-73.

12. Mehrbod P, El Zowalaty M, Omar AR, Hair-Bejo M, Ideris A. Statins reduce the expression of proinflammatory cytokines in influenza a virus infected CrFK cells. Acta Virol. 2012;56(4):353-5.

13. Khalafalla MM, Abdellatef E, Dafalla HM, Nassrallah AA, Aboul-Enein KM, Lightfoot DA, et al. Active principle from moringa oleifera lam leaves effective against two leukemias and a hepatocarcinoma. Afr J Biotechnol. 2010;9(49):8467-71.

14. Mozaffari Nejad AS, Kamkar A, Giri A, Pourmahmoudi AA. Ethnobotany and folk medicinal uses of major trees and shrubs in northern Iran. J Med Plant Res. 2013;7(7):284-9.

15. Amic D, Amie DD, Beslo D, Trinajstic N. Structural-radical scavenging activity relationship of flavonoids. Croat Chem Acta. 2003;76:55-61.

16. Aqil F, Ahmad I, Mehmood Z. Antioxidant and free radical scavenging properties of twelve traditionally used Indian medicinal plants. Turk J Biol. 2006;30:177-83

17. Jalali H, Mozaffari Nejad AS, Ebadi AG, Laey G. Ethnobotany and folk pharmaceutical properties of major trees or shrubs in northeast of Iran. Asian J Chem. 2009;21(7):5632-8.

18. Mehrbod P, Ideris A, Omar AR, Hair-Bejo M. Prophylactic effect of herbalmarine compound (HESA-A) on influenza a virus infectivity. BMC Complem Altern M. 2014;14(1):131.

19. Etienne-Manneville S, Hall A. Rho GTPases in cell biology. Nature. 2002; 420(6916):629-35.

20. Zhang W, Du L, Gunst SJ. The effects of the small GTPase RhoA on the muscarinic contraction of airway smooth muscle result from its role in regulating actin polymerization. Am J Physiol-Cell Physiol. 2010;299:C298-306.

21. Hall A. Rho GTPases and the control of cell behaviour. Biochem Soc T. 2005; 33:891-5.

22. Wang J, Li H, Chen Y, Wei H, Gao GF, Liu H, et al. Transport of influenza virus neuraminidase (NA) to host cell surface is regulated by ARHGAP21 and Cdc42 proteins. J Biol Chem. 2012:287(13):9804-16.

23. Bishop AL, Hall A. Rho GTPases and their effector proteins. Biochem J. 2000; 1(348):241-55

24. Ridley AJ. Rho GTPases and actin dynamics in membrane protrusions and vesicle trafficking. Trends Cell Biol. 2006;16(10):522-9.

25. Hippenstiel S, Schmeck B, N'Guessan PD, Seybold J, Krüll M, Preissner K, et al. Rho protein inactivation induced apoptosis of cultured human endothelial cells. Am J Physiol-Lung Cell Mol Physiol. 2002;283(4):L830-L8.

26. Esteve P, Embade N, Perona R, Jiménez B, del Peso L, León J, et al. Rho-regulated signals induce apoptosis in vitro and in vivo by a p53independent, but Bcl2 dependent pathway. Oncogene. 1998;17(14): 1855-69.

27. Aznar S, Lacal JC. Rho signals to cell growth and apoptosis. Cancer Lett. 2001;165(1):1-10.

28. Palazzolo G, Horvath P, Zenobi-Wong M. The flavonoid isoquercitrin promotes Neurite elongation by reducing RhoA activity. PLoS One. 2012; 7(11):e49979.
29. Lai WW, Hsu SC, Chueh FS, Chen YY, Yang JS, Lin JP, et al. Quercetin inhibits migration and invasion of SAS human oral cancer cells through inhibition of NF-KB and matrix metalloproteinase-2/-9 signaling pathways. Anticancer Res. 2013;33(5):1941-50

30. Schroeter H, Spencer JP, Rice-Evans C, Williams RJ. Flavonoids protect neurons from oxidized low-density-lipoprotein-induced apoptosis involving c-Jun N-terminal kinase (JNK), c-Jun and caspase-3. Biochem J. 2001;358(Pt 3):547-57.

31. Kaul TN, Middleton E, Ogra PL. Antiviral effect of flavonoids on human viruses. J Med Virol. 1985;15(1):71-9.

32. Orhan DD, Özçelik B, Özgen S, Ergun F. Antibacterial, antifungal, and antiviral activities of some flavonoids. Microbiol Res. 2010;165(6):496-504.

33. Zandi K, Teoh BT, Sam SS, Wong PF, Mustafa MR, AbuBakar S. Antiviral activity of four types of bioflavonoid against dengue virus type-2. Virol J. 2011;8(1):560.

34. Kumar S, Pandey AK. Chemistry and biological activities of Fflavonoids: an overview. Sci World J. 2013:2013:1-16.

35. Johari J, Kianmehr A, Mustafa RM, Abubakar S, Zandi K. Antiviral activity of baicalein and quercetin against the Japanese encephalitis virus. Int J Mol Sci. 2012;13(12):16785-95.

36. Cushnie TP, Lamb AJ. Antimicrobial activity of flavonoids. Int J Antimicrob Agents. 2005;26(5):343-56.

37. Ramos FA, Takaishi Y, Shirotori M, Kawaguchi $Y$, Tsuchiya $K$, Shibata H, et al. Antibacterial and antioxidant activities of quercetin oxidation products from yellow onion (Allium cepa) skin. J Agric Food Chem. 2006;54(10):3551-7.

38. Li BQ, Fu T, Dongyan Y, Mikovits JA, Ruscetti FW, Wang JM. Flavonoid Baicalin inhibits HIV-1 infection at the level of viral entry. Biochem Bioph Res Co. 2000;276(2):534-8.

39. Anusuya S, Gromiha MM. Quercetin derivatives as non-nucleoside inhibitors for dengue polymerase: molecular docking, molecular dynamics simulation, and binding free energy calculation. J Biomol Struct Dyn. 2017:35(13):2895-909.

40. Rojas Á, Del Campo JA, Clement S, Lemasson M, García-Valdecasas M, GilGómez A, et al. Effect of Quercetin on hepatitis C virus life cycle: From viral to Host targets. Sci Rep. 2016;6:31777.

41. Wong G, He S, Siragam V, Bi Y, Mbikay M, Chretien M, et al. Antiviral activity

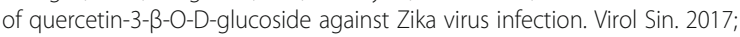
32(6):545-7.

42. Hafidh RR, Abdulamir AS, Jahanshiri F, Abas F, Abu Bakar F, Sekawi Z. Asia is the mine of natural antiviral products for public health. Open Complem Med J. 2009;1:58-68.

43. Dayem AA, Choi HY, Kim YB, Cho SG. Antiviral effect of methylated flavonol isorhamnetin against influenza. PLoS One. 2015;10(3):e0121610.

44. Hossain MK, Choi HY, Hwang JS, Dayem AA, Kim JH, Kim YB, et al. Antiviral activity of 3,4'-dihydroxyflavone on influenza a virus. J Microbiol. 2014;52(6): 521-6.

45. Arena A, Bisignano G, Pavone B, Tomaino A, Bonina FP, Saija A, et al. Antiviral and immunomodulatory effect of a lyophilized extract of Capparis spinosa L. buds. Phytother Res. 2008;22(3):313-7.

46. Chiang LC, Ng LT, Chiang W, Chang MY, Lin CC. Immunomodulatory activities of flavonoids, monoterpenoids, triterpenoids, iridoid glycosides and phenolic compounds of Plantago species. Planta Med. 2003;69(7): 600-4.

47. Aichour R, Charef N, Baghiani A, Arrar L. Immunomodulatory effects of Algerian caper. Int J Pharm Pharm Sci. 2016;8(2):51-4.

48. Miles SL, McFarland M, Niles RM. Molecular and physiological actions of quercetin: need for clinical trials to assess its benefits in human disease. Nutr Rev. 2014;72(11):720-34

49. Wu W, Li R, Li X, He J, Jiang S, Liu S, et al. Quercetin as an antiviral agent inhibits influenza a virus (IAV) entry. Viruses. 2016;8(1):6.

50. Choi HJ, Song JH, Park KS, Kwon DH. Inhibitory effects of quercetin 3rhamnoside on influenza a virus replication. Eur J Pharm Sci. 2009;37(3): 329-33.

51. Lakhanpal P, Rai DK. Quercetin: A versatile flavonoid. Internet J Medic Update. 2007;2:22-37.

52. Anand David AV, Arulmoli R, Parasuraman S. Overviews of biologica importance of quercetin: a bioactive flavonoid. Pharmacogn Rev. 2016; 10(20):84-9.

53. Chun OK, Chung SJ, Claycombe KJ, Song WO. Serum C-reactive protein concentrations are inversely associated with dietary flavonoid intake in U.S. adults. J Nutr. 2008;138(4):753-60. 
54. Mehrbod P, Abdalla MA, Fotouhi F, Heidarzadeh M, Aro AO, Eloff JN, et al. Immunomodulatory properties of quercetin-3-O-a-L-rhamnopyranoside from Rapanea melanophloeos against influenza a virus. BMC Complem Altern M. 2018;18(1):184

55. Mehrbod P, Abdalla MA, Njoya EM, Ahmed AS, Fotouhi F, Farahmand B, et al. South African medicinal plant extracts active against influenza a virus. BMC Complem Altern M. 2018;18(1):112.

56. Bradford MM. A rapid and sensitive method for quantitation of microgram quantities of protein utilizing the principle of protein-dye binding. Anal Biochem. 1976;72:248-54.

57. Liu Z, Zhao J, Li W, Shen L, Huang S, Tang J, et al. Computational screen and experimental validation of anti-influenza effects of quercetin and chlorogenic acid from traditional Chinese medicine. Sci Rep. 2016;6:19095.

58. Zhang Y, Han H, Qiu H, Lin H, Yu L, Zhu W, et al. Antiviral activity of a synthesized shikonin ester against influenza a (H1N1) virus and insights into its mechanism. Biomed Pharmacother. 2017;93:636-45.

59. Bouvier NM, Palese P. The biology of influenza viruses. Vaccine. 2008; 26(Suppl 4):D49-53.

60. Haghani A, Mehrbod P, Safi N, Aminuddin NA, Bahadoran A, Omar AR, et al. In vitro and in vivo mechanism of immunomodulatory and antiviral activity of edible Bird's Nest (EBN) against influenza a virus (IAV) infection. J Ethnopharmacol. 2016;185:327-40.

61. Kozak W, Poli V, Soszynski D, Conn CA, Leon LR, Kluger MJ. Sickness behavior in mice mice deficient in interleukin- 6 during turpentine abcess and influenza pneumonitis. Am J Phys. 1997;272:R621-R30.

62. Egecioglu E, Anesten F, Schéle E, Palsdottir V. Interleukin-6 is important for regulation of core body temperature during long-term cold exposure in mice. Biomed Rep. 2018;9(3):206-12

63. Svitek N, Rudd PA, Obojes K, Pillet S, von Messling V. Severe seasonal influenza in ferrets correlates with reduced interferon and increased IL-6 induction. Virology. 2008;376(1):53-9.

64. Carr MW, Roth SJ, Luther E, Rose SS, Springer TA. CCL2. P Natl Acad Sci USA. 1994:91:3652-6.

65. Herold S, Steinmueller M, von Wulffen W, Cakarova L, Pinto R, Pleschka S, et al. Lung epithelial apoptosis in influenza virus pneumonia: the role of macrophage-expressed TNF-related apoptosis-inducing ligand. J Exp Med. 2008;205(13):3065-77.

66. Lee N, Wong CK, Chan PK, Lindegardh N, White NJ, Hayden FG, et al. Acute encephalopathy associated with influenza a infection in adults. Emerg Infect Dis. 2010;16(1):139-42.

67. Aldridge JR, Moseley CE, Boltz DA, Negovetich NJ, Reynolds C, Franks J, et al. From the cover: TNF/iNOS-producing dendritic cells are the necessary evil of lethal influenza virus infection. P Natl Acad Sci USA. 2009:106:5306-11.

68. Billiau A. Interferon beta in the cytokine network: an anti-inflammatory pathway. Mult Scler J. 1995;1(1):S2-4.

69. Kasper LH, Reder AT. Immunomodulatory activity of interferon-beta. Ann Clin Transl Neur. 2014;1(8):622-31.

70. Donelan NR, Basler CF, García-Sastre A. A recombinant influenza a virus expressing an RNA-binding-defective NS1 protein induces high levels of Beta interferon and is attenuated in mice. J Virol. 2003;77(24):13257-66.

71. Liu D, Mei X, Wang L, Yang X. RhoA inhibits apoptosis and increases proliferation of cultured SPCA1 lung cancer cells. Mol Med Rep. 2017;15(6): 3963-8.

72. Kim YJ, Jung EB, Seo SJ, Park KH, Lee MW, Lee CS. Quercetin-3-O-(2"galloyl)-a-l-rhamnopyranoside prevents TRAIL-induced apoptosis in human keratinocytes by suppressing the caspase-8- and bid-pathways and the mitochondrial pathway. Chem Biol Interact. 2013;204(3):144-q52.

73. Han H, Xu B, Amin A, Li H, Yu X, Gong M, et al. Quercetin3OaLrhamnopyranoside derived from the leaves of Lindera aggregata (Sims) Kosterm. Evokes the autophagyinduced nuclear factor erythroid 2related factor 2 antioxidant pathway in human umbilical vein endothelial cells. Int J Mol Med. 2019;43(1):461-74.

\section{Publisher's Note}

Springer Nature remains neutral with regard to jurisdictional claims in published maps and institutional affiliations.

\section{Ready to submit your research? Choose BMC and benefit from}

- fast, convenient online submission

- thorough peer review by experienced researchers in your field

- rapid publication on acceptance

- support for research data, including large and complex data types

- gold Open Access which fosters wider collaboration and increased citations

- maximum visibility for your research: over $100 \mathrm{M}$ website views per year

At $\mathrm{BMC}$, research is always in progress.

Learn more biomedcentral.com/submissions 